\title{
Suggested Ideas to Manage Produced Water in Southern Iraqi Oil Fields
}

\author{
Ayad A. Al-Haleem, Faleh H. M. Almahdawi and Dhorgham Skban Ibrahim \\ Department of Petroleum Engineering, College of Engineering, \\ University of Baghdad, Baghdad, Iraq
}

\begin{abstract}
The produced water contain mainly an impurities include dissolved salts, oils, grease-proof, different organic and inorganic compounds and Naturally Occurring Radioactive Materials (NORM). This water may have environmental effect or it can be useful for various applications after a special treatment. The management of produced water contains a wide range of options and techniques which try to optimize use of this water and avoid the environmental damage of contaminated water in case of lack of proper handling. In this study, highlight is introduced to know the major trends of produced water which associated with petroleum production in Iraq. Many issues have been suggested to control or prevent the problem of increasing in quantity of produced water. One of the most important suggestion ideas to manage produced water is to reuse water that slightly exceed regulatory limits in arid or drought areas, rather than losing them to discharge in the surrounding lands. Also, for less cost, the produced water can be treated on site to be re-injected back into the formation from where it came. The summary of this study shows the need to inform a data base of quantity and quality of produced water in different Iraqi oil fields and how to benefit of it in compliance with the environmental regulations.
\end{abstract}

Key words: Produced water, oilfield, water management, water treatment, oil production, environmental regulations

\section{INTRODUCTION}

Produced water or associated water is water brought to surface along with the crude oil and gas and separated from oil and gas equipment at the surface. The amount of produced water and the concentrations of contaminants present in usually vary significantly over the lifetime, geological conditions and position of the oil field. It contains many constituents based on what is present in the subsurface at a particular location. It may contain salt, volatile organic compounds, polycyclic aromatic hydrocarbons, heavy metals and Naturally Occurring Radioactive Materials (NORM) (Stephenson, 1992). In addition to naturally occurring impurities, chemical additives like coagulants, corrosion inhibitors, emulsion breakers, biocides, dispersants, paraffin control agents and scale inhibitors are often added to alter the chemistry of produced water (Freeman, 1988). There has been a significant increase in the volume of the produced water during oil and gas extraction. Nearly 1:5 is the ratio of produced water generated in Iraq as a waste byproduct of the crude oil processed (Mousa and Arafat, 2015). Figure 1 shows the volume of produced water generated during oil recovery from 2010-2018 according to the organization of the petroleum exporting countries. It can

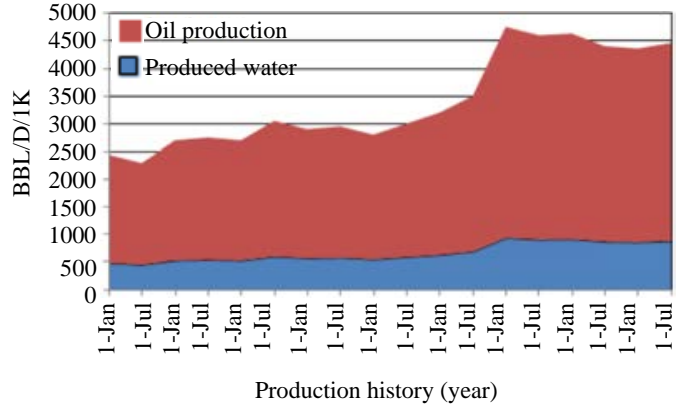

Fig. 1: Iraq crude oil production history

be noticed from the figure that nearly 1 million BBL/day of produced water was associated with oil recovery in 2016 . It is expected to reach 2.5 million $\mathrm{BBL} /$ day with the expected modern management of Iraqi oil sector of production capacity to reach 10 million $\mathrm{BBL} /$ day in the year 2020 .

The produced water associated with crude oil production is an emulsion of water in oil. It has complex constituents which can remove the excess amounts using an appropriate treatment method. A number of methods which vary considerably in their effectiveness and cost are available to treat contaminated water to prepare it for reuse or disposal (Wojtanowicz, 1993). Most of these

Corresponding Author: Dhorgham Skban Ibrahim, Department of Petroleum Engineering, College of Engineering, 
methods are classified into two groups: removal of hydrocarbons and removal of solids with two phases for each group suspended and dissolved. Many methods are available to remove the suspended and dissolved hydrocarbons from produced water which varies in their environmental effect and cost (Ibrahim et al., 2012; Lawrence et al., 1995). Also the same trend can be considered when dealing with the methods of removal of suspended and dissolved salts.

In this study, samples of produced water were collected from five Iraqi oil fields (fifteen oil wells) at southern of Iraq and analyzed for some variables like $\mathrm{pH}$, specific gravity, resistivity, total dissolved salts and concentration of some heavy metals. The aim of this study is to know the main features of produced water in Iraq and review the recent global technologies concerning with management options to make the produced water as useful water source.

\section{MATERIALS AND METHODS}

Field observations: The production of produced water is one of many problems occur in Iraqi oilfield. To overcome this problem, stops the well operations followed by reclamation the well is needed. This option will make a loss in productive time besides an increasing in total costs. The presence of produced water is inevitable during the well life but the unsuccessful production management will accelerate the early history of produced water. In other words, following the right production steps will increase the well production time without reclamation. In some situations, the quantity of produced water increase because of the presence of corrosion in the case of production well or the well penetrate in wrong way the impermeable bed which isolate between the oil zone and the water zone beneath of it or can be attributed to coning or fractures in geological bed that lead to follow of water from faraway locations.

From the field observations, many reasons for the present problem have been noticed among them the following:

- Non-compliance of chock size, since, the increasing in chock size for the purpose of increasing production will associate with unwanted of produced water production

- Selecting of perforated locations nearest to oil-water contact which must be as far as possible

- Weakness of cement bonds which result in flowing of water with oil behind the casing
In a somewhat recent study about the injection wells in southern Iraqi oil fields which include Zubair oil field, Rumaila oil field and West Qurna oilfield, it can be noticed that there is more than one hundred injection wells worker. Also, an Electrical Submersible Pumps (ESP) are used to injection water from the nearest river to Mishrif formation in some wells.

\section{RESULTS AND DISCUSSION}

Practical part: The collected samples are analyzed chemically for their concentration of some heavy metals. Table 1 and 2 represent the chemical results in addition to the values of $\mathrm{pH}$, resistivity and total dissolved salts. It can be seen from the table's results that the dominant ions are sodium and calcium as positive ions, also chloride and sulfates as negative ions. Achieving the various treatment goals requires the use of multiple treatment technologies, including physical, chemical and biological treatment processes (Bayati et al., 2011).

Suggested ideas: To control or prevent the problem of produced water, the following issues are suggested:

- Close the well which produce water in huge quantity for a period of month, then, re-well to work with less chock size

- Isolate the perforated locations which submerged with water, partially or completely by lay cementing plug and try to find other un- submerged production units in the same reservoir or in another reservoir

- Press the cement behind the casing of weak locations or of zero presence of cement.

As a work requirement to create surface facilities for water injection in produced oil reservoirs, it is necessary to make a study to choose the optimal water injection model to avoid loss in production as a result to stop many wells which produce by normal depletion. The quick drop in flowing pressure of bottom hole especially at Mishrif formation of Rumaila oil fields as an example, then, reuse of produced water is preferred to reinjection in production reservoirs instead of reveres water which normally used in other industrial and agricultural applications.

In carbonate reservoirs, it is recommended to apply the 5-spot injection pattern or 4-spot and avoid the peripheral injection or tomography injection due to low permeability in carbonate formation rocks which demand the presence of injection water as close as possible. It is important to mention that the peripheral injection is preferable in an inclined reservoir. 
Table 1: Variable concentrations (in ppm) of produced water in Nhr-Umar formation at fifteen oil wells

\begin{tabular}{llll}
\hline Variables & Min. & Max. & Average \\
\hline pH & 4.7 & 6.77 & 5.66 \\
SP. gravity & 1.1410 & 1.1755 & 1.1622 \\
Resistivity $(\Omega m)$ & 0.0444 & 0.0910 & 0.0568 \\
T.D.S & 220765 & 277658 & 243567 \\
$\mathrm{Na}+$ & 58798 & 89790 & 67865 \\
$\mathrm{Ca}++$ & 12700 & 16543 & 13456 \\
$\mathrm{Mg}++$ & 1500 & 3760 & 2560 \\
$\mathrm{~K}+$ & 510 & 3450 & 1890 \\
$\mathrm{Fe}++$ & 4 & 356 & 180 \\
$\mathrm{Sr}++$ & 400 & 690 & 520 \\
$\mathrm{Cl}-$ & 125765 & 165439 & 150897 \\
$\mathrm{So}^{4}$ & 287 & 1389 & 634 \\
$\mathrm{HCO}^{3-}$ & 14 & 689 & 277 \\
\hline
\end{tabular}

Table 2: Variable concentrations (in ppm) of produced water in Mishrif formation at fifteen oil wells

\begin{tabular}{llll}
\hline Variables & Min. & Max. & Average \\
\hline $\mathrm{pH}$ & 4.2 & 6.8 & 5.80 \\
SP. gravity & 1.1232 & 1.1816 & 1.1503 \\
Resistivity $(\Omega \mathrm{m})$ & 0.0266 & 0.0988 & 0.0544 \\
$\mathrm{~T} . \mathrm{D} . \mathrm{S}$ & 226211 & 282312 & 253231 \\
$\mathrm{Na}+$ & 60523 & 87765 & 72642 \\
$\mathrm{Ca}++$ & 9010 & 16421 & 12300 \\
$\mathrm{Mg}++$ & 1649 & 4666 & 2654 \\
$\mathrm{~K}+$ & 503 & 3800 & 1750 \\
$\mathrm{Fe}+++$ & 4 & 690 & 140 \\
$\mathrm{Sr}++$ & 410 & 1210 & 645 \\
$\mathrm{Cl}-$ & 128018 & 177135 & 151867 \\
$\mathrm{So}^{4}$ & 96 & 1420 & 602 \\
$\mathrm{HCO}^{3-}$ & 40 & 610 & 260 \\
\hline
\end{tabular}

The salinity ratio besides different metals and salts trend to dispose and NORM in which the radium represents the main component in it, all play a significant rule in choosing the proper water management strategy. The Iraqi oilfields characterized by their scattered and include large areas. These fields lie far away from surface water sources like rivers and leaks, besides the need for large quantity of water for drilling operations and human consumption by the field staff. The field areas may contain ground water near the surface or deep reservoir water which has a wide range of salinities. In general, there is no data base about the quantity and quality of produced water in Iraq. The salinity of reservoir water in Southern Iraqi oil fields varies from one field to another. For example, the reservoir water in the lahus oil field is salinity water and the sulfate ion is the most prevalent with total dissolved material concentration range between $2500-6200 \mathrm{mg} / \mathrm{L}$ where as the reservoir water in both of South and North Rumaila is very saline water with a concentration range from $195000-290000 \mathrm{mg} / \mathrm{L}$.

To enhance the well productivity and to minimize the water ratio, we have to choose one of the methods which used to isolate the formation water in the well. The water source and its depth are very important issues to select the optimum water isolation solution method. Among of these methods the following:
Isolation by cement: There are many different applied methods which can be used to isolate the formation water that invade the well using the cement material and we can select the following (Ibrahim and Almahdawi, 2016).

Cement plug: This method is applied by injecting the cement slurry through the production pipes followed by water injection until the cement reaches the bottom of the well and cover all the areas which must be isolated. Then the pipes are lifted and a process of reserve circulation to remove the excessive amount of cement and clean the pipes. A certain test should be done after one or two days to examine the height and resistance stillness of cement. If the resistance shows a negative sign, a cement process must be returned. To test the permeability of cement plug we have to expose the well tubes to differential internal pressure or internal not to exceed the well test pressure.

Squeeze cementing: This process is applied to set up a barrier layer against water offers which almost happened synchronizing with build up of cement plug.

Squeeze cementing without the use of an insulator: The process is applied at pressures borne by the packing pipes and production and surface equipment. Such method can be summarized as following steps; make an experiment to define layer acceptance. Make a rotation in the well for the purpose of well cleaning. Inject a suitable quantity of cement into the well. The selection of cement quantity depends on the ability of the layer to accept through the production pipes which their ends located at the bottom of the well. Displace this quantity of cement by displacement liquid until it reaches the bottom. Close the annuals and repeated the injection and displacement of liquid into the well which leads to increase the pressure and the cement liquid will be forced to inter the located layer.

Cementing under pressure using an insulator: This process applies in cases that require high pressures to inject liquid cement in the layer which may affect the production packing pipes. If these pipes have a life of great service within the well, then, these pipes must provide with packer at the lower end and the annuals must be closed and a discharge link is placed above the insulator for the rotation of the liquid between production pipes and annuals above the insulator. Certainly, after that the same steps which applied in cementing under pressure process without using insulator that must be followed. 
Oily cement: The amount of oily cement is determined according to experimental data from the well itself. The density of cement sample can be about $1.5-1.8 \mathrm{~g} / \mathrm{cm}^{3}$. After applying the injection process and drying, examining the cementing process by analyzing samples of well production which must be taken to find the reduction in water ratio.

Method of selective isolation: This method depends on using silicates, for example, using sodium silicate alkaline $\mathrm{Na}_{2}$ Sio which is recommended to use in wells where the water ratio was reached to high ratios which caused sealing fractures and result in transmission of water.

\section{CONCLUSION}

The management of produced water due to the recent and current technologies may be summarized as follows; to control or prevent the problem of increasing in quantity of produced water, many issues can be suggested among of them the following: close the well which produce water in huge quantity for a period of month, then re-well to work with less chock size.

Isolate the perforated locations which submerged with water, partially or completely by lay cementing plug and try to find other un-submerged production units in the same reservoir or in another reservoir.

Press the cement behind the casing of weak locations or of zero presence of cement. The produced water treatment methods can be classified to select the optimum management option according to the type of contaminants namely suspended and dissolved hydrocarbons and suspended and dissolved solids. Produced water is responsible for a variety of problems in oil field operations such as corrosion, scale, microbial growth, suspended particles and dirty equipment. These problems can be avoided or minimized by applying the appropriate management method.

Generally, many of world wide treatment options should be discussed in any study for their applications in petroleum industry involving costs and environmental effects.

The results of chemical analysis in this study showed that in addition to salt, many produced waters also contain high levels of some heavy metals. Potassium, magnesium, barium, sodium, strontium, chloride, calcium and lead were found to have the highest concentrations.

The treated water with a certain level of purity is very essential at most of drilling sites and for injection water projects. It was found that most of recent management technologies have both of the issues: environmental protection and economical benefit. Moreover, all the technical techniques are designed to achieve the mandate of zero discharge into the environment.

\section{SUGGESTIONS}

One of the most suggested ideas to manage produced water is to reuse water that slightly exceed regulatory limits in arid or drought areas, rather than losing them to discharge in the surrounding lands.

\section{ACKNOWLEDGEMENT}

The researchers would like to acknowledge the support of the Petroleum Engineering Department, University of Baghdad, Iraq, towards this research.

\section{REFERENCES}

Bayati, F., J. Shayegan and A. Noorjahan, 2011. Treatment of oilfield produced water by dissolved air precipitation/solvent sublation. J. Pet. Sci. Eng., 80: 26-31.

Freeman, H.M., 1988. Standard Handbook of Hazardous Waste Treatment and Disposal. McGraw-Hill, New York.

Ibrahim, D.S. and F.H. Almahdawi, 2016. Addition of super absorbent polymer for upgrading of cement quality in Iraqi oil wells. Iraqi J. Chem. Pet. Eng., 17: 83-90.

Ibrahim, D.S., N. Sakthipriya and N. Balasubramanian, 2012. Electro-coagulation treatment of oily wastewater with sludge analysis. Water Sci. Technol., 66: 2533-2538.

Lawrence, A.W., J.A. Miller, D.L. Miller and T.D. Hayes, 1995. Regional assessment of produced water treatment and disposal practices and research needs. Proceedings of the 1995 International Conference on SPE/EPA Exploration and Production Environmental, March 27-29, 1995, Society of Petroleum Engineers, Houston, Texas, pp: 1-20.

Mousa, K.M. and S.A. Arafat, 2015. Experimental study on treatment of produced water. J. Chem. Eng. Proc. Technol., 6: 1-5.

Stephenson, M.T., 1992. Components of produced water: A compilation of industry studies. J. Pet. Technol., 44: 548-603.

Wojtanowicz, A.K., 1993. Oilfield environmental control technology: A synopsis. J. Pet. Technol., 45: 166-173. 